\title{
Catalytic Behavior of Brønsted Acid Sites in MWW and MFI Zeolites with Dual Meso- and Microporosity
}

\author{
Dongxia Liu, $^{\dagger}$ Aditya Bhan, ${ }^{*,+}$ Michael Tsapatsis, ${ }^{*,+}$ and Saleh Al Hashimi ${ }^{\neq}$ \\ ${ }^{\dagger}$ Department of Chemical Engineering and Materials Science, University of Minnesota, 421 Washington Avenue SE, \\ Minneapolis, Minnesota 55455, United States \\ ${ }^{\ddagger}$ Chemical Engineering Program, The Petroleum Institute, Abu Dhabi, United Arab Emirates
}

Supporting Information

\begin{abstract}
The catalytic behavior of Brønsted acid sites in three acidic zeolite materials (one MWW and two MFI zeolites) containing dual meso-/microporosity was studied using ethanol dehydration and monomolecular conversion of propane and isobutane as probe reactions. The meso-/microporous MWW zeolite, MCM-36 or pillared MWW, consists of a zeolitic layer structure, with independent microporosity and mesoporosity within the layers and between the layers, respectively. A meso-/microporous MFI (pillared MFI) zeolite also contains a zeolitic layer structure, but with interconnected micropore and mesopore systems. A different meso-/microporous MFI zeolite, three-dimensionally ordered mesoporous-imprinted (3DOm-i) MFI, contains nanometer-sized spherical elements forming an opaline structure, with highly interconnected meso- and micropores. The rate and apparent
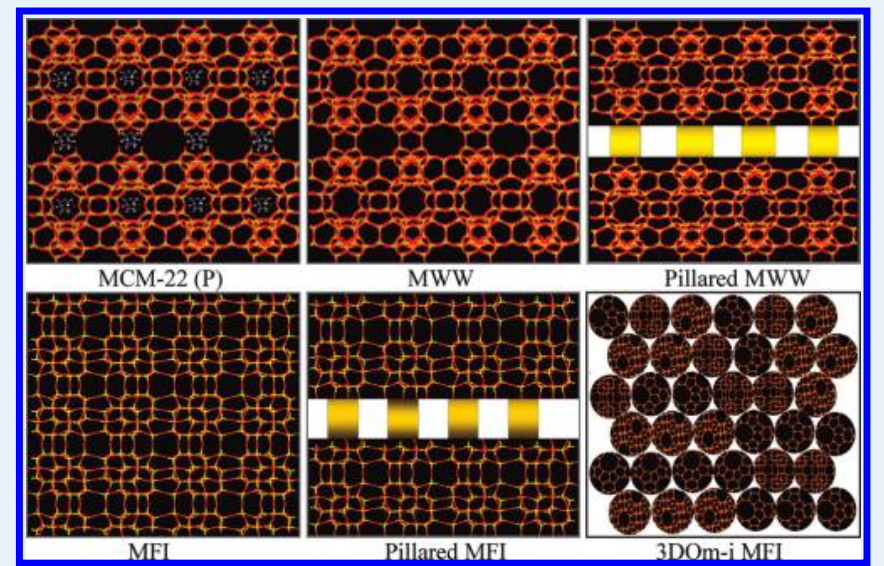
activation energy of the catalytic probe reactions in zeolites possessing dual meso- and microporosity was comparable to conventional microporous MCM-22 (MWW) and MFI materials. This similarity in kinetic behavior between materials possessing dual meso-/microporosity and their microporous analogues when assessed under conditions of strict kinetic control implies that the catalytic behavior of Brønsted acid sites in materials with dual meso-/microporosity is preferentially dominated by the microporous environment possibly because it provides a better fit for adsorption of small alkane or alcohol reactant molecules.
\end{abstract}

KEYWORDS: meso-/microporous zeolite, hierarchical materials, shape selectivity, monomolecular alkane conversion, ethanol dehydration, propane activation, isobutane activation, base titration

\section{INTRODUCTION}

Crystalline microporous zeolites are widely used as heterogeneous catalysts in petrochemical and fine chemical synthesis mainly because of their high surface area, high adsorption capacity, and well-defined micropores that are responsible for shape selectivity. ${ }^{1-6}$ In certain cases, however, the catalytic applications of zeolites are limited by mass transport in the microporous network when reactions of bulky molecules are concerned. $^{2,7}$ The relatively small sizes of micropores $(<2 \mathrm{~nm})$ impose restricted access and slow transport to/from the active sites, which renders low utilization of the zeolite active volume. ${ }^{8-10}$ Inclusion of mesopores into microporous zeolites has been explored to create meso-/microporous zeolites with improved pore accessibility and molecular transport to overcome such mass transport limitations. In recent years, meso-/microporous zeolites have been obtained by exfoliation ${ }^{11}$ or pillaring of layered zeolites, ${ }^{12-14}$ by growth of zeolites in templates, ${ }^{15-18}$ by desilication $^{19}$ or dealumination ${ }^{20}$ processes, and by synthesizing very thin zeolite nanosheets. ${ }^{21}$
Recently, three meso-/microporous zeolites (pillared MWW, pillared MFI, and three-dimensionally ordered mesoporousimprinted (3DOm-i MFI) were synthesized and were investigated for textural properties of the zeolite membrane, adsorption, and catalytic applications. ${ }^{14,18,22,23}$

Pillared MWW, derived from a layered precursor, MCM$22(\mathrm{P})$, is the first pillared zeolite material with microporous layers and mesoporous interlayer spaces. ${ }^{12}$ For synthesis of pillared MWW, layers of MCM-22(P) are expanded by use of a surfactant, and then intercalated by silica species which convert into inorganic pillars upon condensation and hold the layers apart creating interlayer mesopores. ${ }^{13,24-26}$ We have previously reported a mild swelling of MCM-22(P) under room temperature conditions, which results in preservation of the MWW layer structure and composition. ${ }^{14}$

Received: October 10, 2010

Revised: November 18, 2010

Published: December 10, 2010 
Using a similar pillaring procedure to that of swollen MCM22(P), Ryoo and co-workers pillared multilamellar MFI nanosheets ${ }^{27}$ that were created through coherent assembly of the zeolite layer and the structure directing agent, a diquaternary ammonium surfactant with relatively long hydrocarbon chains. ${ }^{21}$ The silica pillars retain the interlamellar spaces of the multilamellar MFI upon removal of the surfactant by calcination.

A templating approach was used to synthesize meso-/microporous MFI zeolite with imprinted 3DOm-i features. ${ }^{18}$ Highly ordered mesoporous carbon (3DOm Carbon) ${ }^{28}$ with interconnected pore space served as the template. The $3 \mathrm{DOm}$ carbon was synthesized by replication of colloidal crystals composed of size-tunable silica nanoparticles. ${ }^{29,30}$ 3DOm-i MFI zeolites with a wide range of meso-porosities (mesopore size from $\sim 5 \mathrm{~nm}$ to $\sim 13 \mathrm{~nm}$ ) were synthesized through confined growth within 3DOm carbon. ${ }^{31}$

Pillared MWW, pillared MFI, and 3DOm-i MFI zeolites are highly crystalline materials possessing dual meso- and microporosity features so that these materials are potentially capable to improving zeolite pore accessibility and mass transport in catalytic applications.

In the present work, we assess the accessibility and catalytic properties of acidic hydroxyl groups in meso-/microporous pillared MWW, pillared MFI, and 3DOm-i MFI zeolites. The location of Brønsted acid sites in zeolite micropores has catalytic consequences for the selectivity and rates of chemical reactions ${ }^{6-8}$ and confinement effects also play a dominant role in the adsorption of hydrocarbons in zeolite environments. ${ }^{32-35}$ Therefore, the kinetic and thermodynamic parameters in the meso-/microporous zeolites may differ significantly from that of conventional microporous materials. Emerging reports on meso-/microporous zeolites have shown enhanced catalytic behavior for meso-/ microporous zeolites in comparison with conventional microporous materials. ${ }^{17,21}$ However, it remains unclear whether this enhanced catalytic behavior arises because of enhanced transport characteristics of these materials or because of higher intrinsic rate or equilibrium parameters. In our study, we rigorously eliminate transport artifacts and specifically aim to answer the question: Under conditions of strict kinetic control, are Brønsted acid sites in materials possessing dual meso-/microporosity more or less reactive than Brønsted acid sites circumscribed in a microporous zeolite environment? The number of Brønsted acid sites contained within each catalyst was assessed in chemical titration studies using dimethyl ether (DME), pyridine, and 2,6-di-tert-butylpyridine (DTBP) as probe molecules. The catalytic behavior of the meso-/microporous zeolites was evaluated by ethanol dehydration reactions and monomolecular activation of propane and isobutane. Ethanol dehydration reactions have been suggested as a useful probe to evaluate catalytic consequences of acid site environment of zeolite catalysts. ${ }^{36,37}$ Monomolecular alkane reactions are useful probes of the catalytic behavior of Brønsted acid sites in zeolites because they form relatively unreactive primary products of cracking and dehydrogenation events. $^{38-42}$ The rate parameters for alkane activation were interpreted using thermochemical cycles that define the contributions of enthalpy and entropy to chemical reactions catalyzed by Brønsted acids. ${ }^{43}$ For comparison to zeolites consisting exclusively of microporous features, the rate and selectivity of Brønsted acid sites for ethanol, propane, and isobutane reactions were investigated for MCM-22 (conventional MWW) and ZSM-5 (conventional MFI) under the same experimental conditions. For simplicity in nomenclature, MCM-22 and
ZSM-5 are designated as MWW and MFI, respectively, in the remainder of this paper.

\section{EXPERIMENTAL SECTION}

2.1. Preparation of Catalysts. Synthesis of MWW and Pillared MWW Zeolites. MWW and pillared MWW were derived from the same precursor, MCM-22(P). The hydrothermal synthesis of MCM-22(P) was carried out by using the method described by Corma et al. ${ }^{11,44}$ One portion of the crystalline product MCM-22 (P) was dried and calcined to produce MWW. The other portion of MCM-22(P) was swollen according to the method developed by Maheshwari et al., ${ }^{14}$ followed by pillaring of the swollen materials using the procedure reported by Barth et al. ${ }^{45}$ The resulting solid was treated using the same conditions as those for MWW to produce pillared MWW.

Synthesis of Pillared MFI and 3DOm-i MFI Zeolites. A multilamellar MFI was synthesized using the method reported by Ryoo and co-workers. ${ }^{21}$ Pillaring of multilamellar MFI was done as reported by $\mathrm{Na}$ et al. ${ }^{27}$ to produce pillared MFI. 3DOm-i MFI was synthesized using the method reported by Lee et al. ${ }^{31}$ After steam assisted crystallization, the $3 \mathrm{DOm}$ carbon templates containing the synthesized 3DOm-i MFI zeolite was heated at $0.0167 \mathrm{~K} \mathrm{~s}^{-1}$ under a flow of dry $\mathrm{N}_{2}$ to $823 \mathrm{~K}$ and kept at this temperature for $10 \mathrm{~h}$ to decompose the structure directing agent. Conventional ZSM-5 zeolite, designated as MFI, was purchased from Zeolyst (CBV 8014), and was used as a microporous MFI sample for comparison. Details on the synthesis of MWW- and MFI-type zeolites are described in section S1 of the Supporting Information.

Ion-Exchange of Zeolite Catalysts. The as-synthesized MWW, pillared MWW, pillared MFI, and 3DOm-i MFI residing in $3 \mathrm{DOm}$ carbon were ion-exchanged four times using $1 \mathrm{M}$ aqueous $\mathrm{NH}_{4} \mathrm{NO}_{3}$ (weight ratio of zeolite to $\mathrm{NH}_{4} \mathrm{NO}_{3}$ solution $=1: 10$ ) at $353 \mathrm{~K}$ for $12 \mathrm{~h}$, and subsequently, filtered by vacuum, washed with deionized water three times, and dried at $343 \mathrm{~K}$ overnight. No ion-exchange process was applied to the conventional MFI since it was purchased in the $\mathrm{NH}_{4}{ }^{+}$form. All zeolite samples in their $\mathrm{NH}_{4}{ }^{+}$form were treated in dry air $(1.67$ $\mathrm{cm}^{3} \mathrm{~s}^{-1}$, ultrapure, Minneapolis Oxygen) by increasing the temperature from ambient to 773 at $0.167 \mathrm{~K} \mathrm{~s}^{-1}$ and holding for $4 \mathrm{~h}$ to thermally decompose $\mathrm{NH}_{4}{ }^{+}$to $\mathrm{NH}_{3}$ and $\mathrm{H}^{+}$. The 3DOm-i MFI sample was kept at $773 \mathrm{~K}$ for $16 \mathrm{~h}$ to ensure complete removal of the $3 \mathrm{DOm}$ carbon template. The resultant proton-form zeolites were pelleted, crushed, and sieved to retain particle sizes between 180 and $425 \mu \mathrm{m}$ (40-80 mesh). All catalytic reactions were carried out after converting zeolites into the proton-form.

2.2. Catalyst Characterization. Textural Property Investigation. $\mathrm{N}_{2}$ adsorption/desorption measurements were carried out at $77 \mathrm{~K}$ on an Autosorb-1 analyzer (Quantachrome Instruments). Prior to the measurement, samples were evacuated overnight at $573 \mathrm{~K}$ and $1 \mathrm{mmHg}$ pressure. Si and $\mathrm{Al}$ contents were determined by inductively coupled plasma optical emission spectroscopy (ICP-OES, Galbraith Laboratories). ${ }^{27} \mathrm{Al}$ MAS NMR spectra were recorded at $130.34 \mathrm{MHz}$ using $4 \mathrm{~mm}$ rotors at $14 \mathrm{kHz}$ spinning speed, a dwell time of $0.5 \mu \mathrm{s}$, a selective $\pi / 18$ pulse of $0.3 \mu \mathrm{s}$, and a recycle delay of $0.1 \mathrm{~s}$ at a field of $11.7 \mathrm{~T}$ (BRUKER Avance 500). An aqueous solution of aluminum sulfate $(0.1 \mathrm{M})$ was used as the external reference $(0 \mathrm{ppm})$. Scanning electron microscopy (SEM), powder X-ray diffraction (XRD), and small-angle X-ray diffraction (SAXD) measurements were 


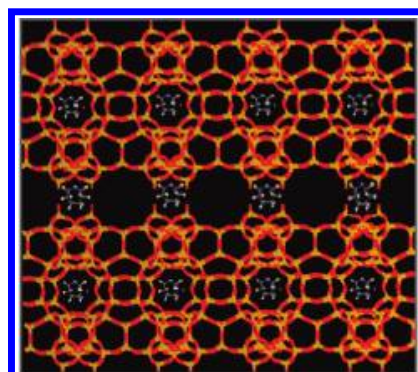

(a) MCM-22 (P)

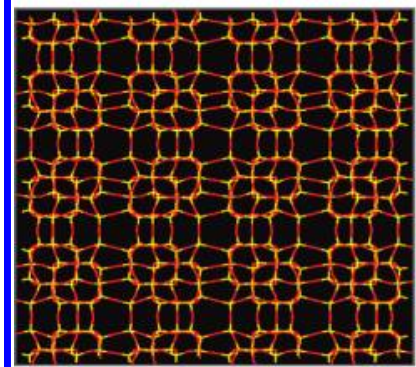

(d) MFI

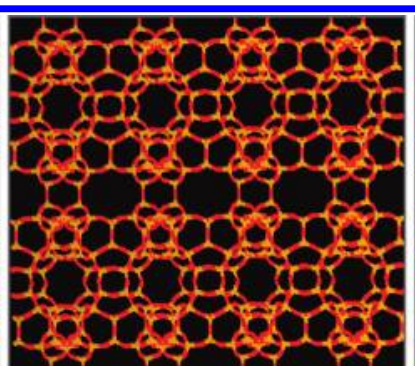

(b) MWW

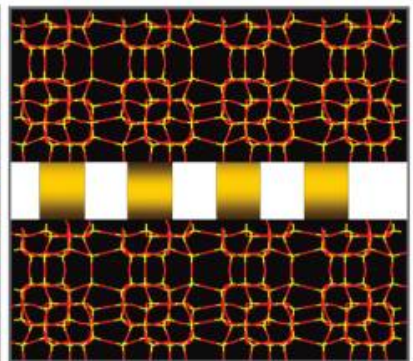

(e) Pillared MFI

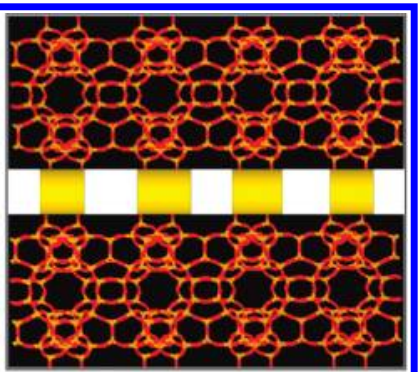

(c) Pillared MWW

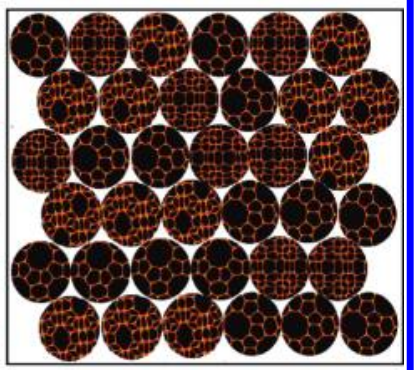

(f) 3DOm-i MFI

Figure 1. Schematic illustration of zeolite structures: (a) MCM-22 (P), (b) MWW, (c) Pillared MWW, (d) MFI, (e) Pillared MFI, and (f) 3DOm-i MFI catalysts. MCM-22 (P), MWW, and Pillared MWW viewed parallel to the microporous layer; MFI and Pillared MFI viewed along the $c$-axis direction; 3DOm-i MFI viewed along unspecified direction. Silica pillars are highlighted in yellow in pillared MWW and pillared MFI zeolites. Structure directing agents are shown in white for MCM-22 (P). Each sphere in 3DOm-i MFI represents one individual spherical element.

also employed to investigate the textural properties of the zeolite catalysts. Details on these characterizations are included in section S2.1 of the Supporting Information.

Assessment of the Number of Brønsted Acid Sites. The number of Brønsted acid sites in each zeolite sample was determined by chemical titration using DME by following a reported procedure. ${ }^{46,47}$ Details on the DME titration experiment can be referred to section S2.2 of the Supporting Information.

2.3. Catalytic Probe Reactions. Ethanol Dehydration Reactions. The experimental set up described for DME chemical titration studies was used for studying ethanol dehydration reactions on zeolite samples. Catalyst samples $(0.015 \mathrm{~g}-0.100$ g) diluted with acid-washed quartz particles ( $0.5 \mathrm{~g}-0.8 \mathrm{~g}$, 160-630 $\mu \mathrm{m}$, European Commission) were treated in $\mathrm{He}$ $\left(0.0083 \mathrm{~cm}^{3} \mathrm{~s}^{-1}\right.$, ultrapure, Minneapolis oxygen) at $773 \mathrm{~K}$ $\left(0.0167 \mathrm{~K} \mathrm{~s}^{-1}\right)$ for $3 \mathrm{~h}$ prior to cooling in He flow to the reaction temperature. Steady-state ethanol dehydration reactions were carried out under atmospheric pressure, in a temperature range of $363-413 \mathrm{~K}$, and under conditions of differential conversion $(<2.0 \%) \cdot \mathrm{C}_{2} \mathrm{H}_{5} \mathrm{OH}$ ( $\geq 99.5 \%$, Sigma-Aldrich) reactants were introduced into flowing gas streams as a liquid using a syringe pump (Cole Parmer 74900 series). Liquid ethanol $(2.85 \times$ $\left.10^{-7}-2.4 \times 10^{-6} \mathrm{~mol} \mathrm{~s}^{-1}\right)$ was vaporized at $383 \mathrm{~K}$ into a gas flow which contained $\mathrm{He}\left(0.55-9.4 \mathrm{~cm}^{3} \mathrm{~s}^{-1}\right.$ at normal temperature and pressure, NTP, condition) and $\operatorname{Ar}\left(0.0137-0.0297 \mathrm{~cm}^{3}\right.$ $\mathrm{s}^{-1}$ at NTP condition, Minneapolis oxygen) as internal standard; transfer lines were maintained at temperatures greater than $343 \mathrm{~K}$ by resistive heating to prevent any condensation. The partial pressure of ethanol and the product diethyl ether (DEE) was always kept below their respective vapor pressures at ambient temperature to prevent condensation. A gas chromatograph (Agilent HP-5890 GC, Series II) equipped with a methylsiloxane capillary column ( $\mathrm{HP}-1,50.0 \mathrm{~m} \times 320 \mu \mathrm{m} \times 0.52 \mu \mathrm{m})$ connected to a flame ionization detector and a packed column
(SUPELCO HAYESEP R 80/100 mesh packed column, $12 \mathrm{ft}$ ) connected to a thermal conductivity detector was used to calibrate and separate the reactants and products.

Monomolecular Conversion of Propane and Isobutane. Steady-state propane and isobutane conversion was measured on proton-form zeolite catalysts under differential conversion (0.1-2.0\%). Propane (99.99\% purity, Praxair Distribution Inc., $\left.0.0053-0.0883 \mathrm{~cm}^{3} \mathrm{~s}^{-1}\right)$ or isobutane $\left(0.0053-0.0883 \mathrm{~cm}^{3} \mathrm{~s}^{-1}\right.$ at NTP condition, chemically pure, MATHESON TRI-GAS) diluted in Ar and He was sent via heated transfer lines held at 343 $\mathrm{K}$ to the reactor and the effluent to the GC for analysis as described above. Reactant flows were varied $\left(10^{-6}-10^{-4} \mathrm{~mol}\right.$ alkane $\left.\mathrm{g}^{-1} \mathrm{~s}^{-1}\right)$ to probe primary and secondary pathways and any contributions from bimolecular or secondary reactions. The absence of bimolecular pathways and secondary reactions was confirmed by the equimolar ratios of cracking products $(1.0 \pm$ $0.1)$ measured for $\mathrm{C}_{3} \mathrm{H}_{8}\left(\mathrm{C}_{2} \mathrm{H}_{4} / \mathrm{CH}_{4}\right)$ and for $i-\mathrm{C}_{4} \mathrm{H}_{10}\left(\mathrm{C}_{3} \mathrm{H}_{6} /\right.$ $\mathrm{CH}_{4}$ ) reactants, which did not depend on space velocity, and by the absence of hydrocarbons larger than the respective alkane reactants. Activation energies and pre-exponential factors for monomolecular activation of propane or isobutane were obtained from rate constants measured as a function of temperature. Rates and selectivity measured after $24 \mathrm{~h}$ on stream for propane and after about $10 \mathrm{~h}$ on stream for isobutane were similar (within 5\%) to those at the start of each experiment on all catalyst samples, indicating that deactivation did not influence rate measurements. Transport corruptions of measured rates because of the external diffusion and internal diffusion limitations were ruled out using Mears criteria and the Thiele modulus and effectiveness factor, respectively. A detailed analysis of the external and internal diffusion limitations is shown in section S.3 and S.4, respectively, of the Supporting Information.

Base Titration during Ethanol Dehydration Reaction. The experimental set up and reaction conditions for base titration of 
Table 1. Structural and Porosity Characteristics of MWW and MFI Zeolite Catalysts

\begin{tabular}{|c|c|c|c|c|c|c|c|}
\hline zeolite & $\mathrm{Si} / \mathrm{Al}$ ratio $^{a}$ & $\begin{array}{c}\text { Brønsted acid } \\
\text { sites }^{b}(\mathrm{mmol} / \mathrm{g})\end{array}$ & $\begin{array}{c}\text { Brønsted acid } \\
\text { sites }^{c}(\mathrm{mmol} / \mathrm{g})\end{array}$ & $\mathrm{Al}_{\mathrm{EF}}{ }^{d}(\%)$ & $\begin{array}{c}\text { cumulative } \\
\text { pore } \operatorname{vol}^{e}(\mathrm{cc} / \mathrm{g})\end{array}$ & $\begin{array}{l}\text { micropore } \\
\text { vol }^{f}(\mathrm{cc} / \mathrm{g})\end{array}$ & $\begin{array}{l}\text { mesopore } \\
\text { size }^{g}(\mathrm{~nm})\end{array}$ \\
\hline MWW & 15 & 1.02 & 0.55 & & 0.20 & 0.13 & \\
\hline pillared MWW & 20 & 0.78 & 0.32 & & 0.38 & 0.12 & 1.8 \\
\hline MFI & 43 & 0.38 & 0.41 & & 0.20 & 0.13 & \\
\hline pillared MFI & 71 & 0.23 & 0.22 & $16 \%$ & 0.31 & $0.11^{f}$ & 2.8 \\
\hline 3DOm-i MFI & 64 & 0.25 & 0.20 & $18 \%$ & 0.28 & 0.12 & 6.0 \\
\hline
\end{tabular}

${ }^{a}$ Determined from elemental analysis (ICP-OES, Galbraith Laboratories). ${ }^{b}$ Calculated based on $\mathrm{Si} / \mathrm{Al}$ ratio in each sample. ${ }^{c}$ Determined by dimethyl ether titration. ${ }^{d}$ Extra-framework $\mathrm{Al}$ content $\left(\mathrm{Al}_{\mathrm{EF}}\right)$ determined from ${ }^{27} \mathrm{Al} \mathrm{MAS}$ NMR spectra. ${ }^{e}$ Cumulative pore volume and micropore volume of pillared MFI determined using Saito-Foley method. ${ }^{f}$ Micropore volume determined by t-plot method. ${ }^{g}$ Mesopore size calculated from the adsorption branch by the BJH model.

acid sites during ethanol dehydration reactions were the same as those described for ethanol dehydration reactions except that the reaction temperature was fixed at $415 \mathrm{~K}$ and a liquid mixture of organic base pyridine (Aldrich, $99.9 \%$ purity) or 2,6-di-tertbutylpyridine (DTBP, Alfa, 98\% purity) with ethanol was used in the reaction. Liquid mixtures of ethanol with pyridine or DTBP were prepared using $10 \mathrm{~mL}$ of ethanol and $10-20 \mu \mathrm{L}$ of organic base. The dehydration rate was measured at constant intervals as titrant was continuously added until it reached a plateau indicating that acid sites accessible to the titrant became saturated with the organic base. The loss in dehydration rate after saturation by the titrant given by the difference between the initial and the residual rates was used to calculate the number of active sites accessed by the base titrant. The uptake of DTBP titrant by the catalyst was measured from its concentration in the effluent, recorded by gas chromatography, using the same chromatographic protocols as for ethanol dehydration. The uptake of the titrant (per Brønsted acid site) was compared with the loss in rate of ethanol dehydration (per Brønsted acid site) to assess whether pore blockage/accessibility of Brønsted acid sites was a major contributing factor to the observed loss in the rate of ethanol dehydration.

\section{RESULTS AND DISCUSSION}

3.1. Structures of Zeolite Catalysts. Figure 1 shows the schematic structures of MWW, pillared MWW, MFI, pillared MFI, and 3DOm-i MFI zeolites used in the study. MWW and pillared MWW are derived from the same precursor, MCM-22 (P), which possesses a unique layered structure, as shown in Figure 1a. Within the layers, MCM-22 (P) contains twodimensional sinusoidal, 10-membered ring (10 MR) channels (diameters $4.1 \times 5.1 \AA$ ) running parallel to the layer's basal plane. Perpendicular to the layers, MCM-22 (P) contains hourglass shaped pores with $12 \mathrm{MR}$ openings at the entrance and $6 \mathrm{MR}$ channels at the central constrictions. ${ }^{48}$ The topotactic connection of the layers of MCM-22 (P) upon calcination creates zeolite MWW, forming an independent two-dimensional pore system between the layers while the pore system within the layers keeps intact. As shown in Figure 1b, the pore system between the layers of MWW consists of larger supercages (12 MR channels with dimensions $7.1 \times 7.1 \times 18.1 \AA$ ) formed by connection of hourglass shaped pores in MCM-22 (P), which can be accessed by slightly distorted elliptical $10 \mathrm{MR}$ windows $(4.0 \times 5.5 \AA)$ between layers, but not by the $10 \mathrm{MR}$ channels within the layers because of the $6 \mathrm{MR}$ constriction. ${ }^{48}$ Prior to calcination, the layers of MCM-22 (P) can be pillared with $\mathrm{SiO}_{2}$ to keep the interlayer separation, while the void space created between layers produces a mesopore system. ${ }^{49}$ As shown in Figure 1c, the pillared MWW contains the $10 \mathrm{MR}$ channels and hourglass shaped pores within the intact layers and mesopores between layers, while the $6 \mathrm{MR}$ channel constricts the traffic between mesopores and the $10 \mathrm{MR}$ pore system within layers. MFI zeolite consists of two interconnected $10 \mathrm{MR}$ pore systems: one is a straight channel running along the $b$-axis direction $(5.3 \times 5.6 \AA)$; and the other is a zigzag channel running parallel to the $a$-axis $(5.1 \times 5.5 \AA)$. Figure $1 \mathrm{~d}$ shows the structure of MFI zeolite viewed along the $c$-axis direction. The pillared MFI contains mesopores created by the $\mathrm{SiO}_{2}$ pillars running between layers, parallel to the zigzag channels and perpendicular to the straight channel within the layers, ${ }^{27}$ as shown in Figure 1e. In contrast with pillared MWW, molecular traffic is allowed between mesopores and the $10 \mathrm{MR}$ pore system within the layers since the MFI layers are penetrated by the straight $10 \mathrm{MR}$ channels. The structure of 3DOm-i MFI, as shown in Figure 1f, consists of spherical elements forming an opaline structure, in which each element is connected with the 12 other adjacent elements. ${ }^{18,31}$ The mesoporous space created between the ordered spherical elements in 3DOm-i MFI is highly connected and communicates with the micropores present in each spherical element.

3.2. Properties of Zeolite Catalysts. The cumulative pore volume, micropore volume, and mesopore size of the zeolite catalysts were estimated from the $\mathrm{N}_{2}$ adsorption/desorption isotherms (shown in S5 of Supporting Information). The meso-/ microporous zeolites have larger cumulative pore volumes than those of microporous zeolites. The data reported in Table 1 show that the cumulative pore volume of pillared MWW is higher than that of MWW by a factor of 2, and that the cumulative pore volume of pillared MFI and 3DOm-i is higher than that of MFI by a factor of 1.5. The creation of mesopores in the meso-/ microporous zeolites, however, does not result in a loss of micropore volume. As shown in Table 1, the meso-/mico-porous zeolites only show a slight decrease $(\sim 10 \%)$ in the micropore volume compared to their microporous zeolite analogues. The mesopore sizes of pillared MWW, pillared MFI, and 3DOm-i MFI, calculated from the adsorption branch of $\mathrm{N}_{2}$ adsorption/desorption isotherms by the Barret-JoynerHalenda (BJH) model are $1.8 \mathrm{~nm}, 2.5 \mathrm{~nm}$, and $6.0 \mathrm{~nm}$, respectively. Table 1 also shows the $\mathrm{Si} / \mathrm{Al}$ ratio in the zeolites measured by ICP analysis. The meso-/microporous zeolite samples used in this study have mainly tetrahedrally coordinated aluminum, which generates a Brønsted acid site, as shown by ${ }^{27} \mathrm{Al}$ MAS NMR data reported in the Supporting Information for pillared MFI and 3DOm-i MFI, and in the report by Maheshwari et al. ${ }^{22}$ for pillared MWW. The number of Brønsted acid sites in 
Table 2. Rate Constants $\left(k_{\text {meas }}\right)$ of DEE Production at $383 \mathrm{~K}$, Measured Activation Energy $\left(E_{\text {meas }}\right)$ and Entropy of DEE Synthesis over MWW and MFI Zeolite Catalysts

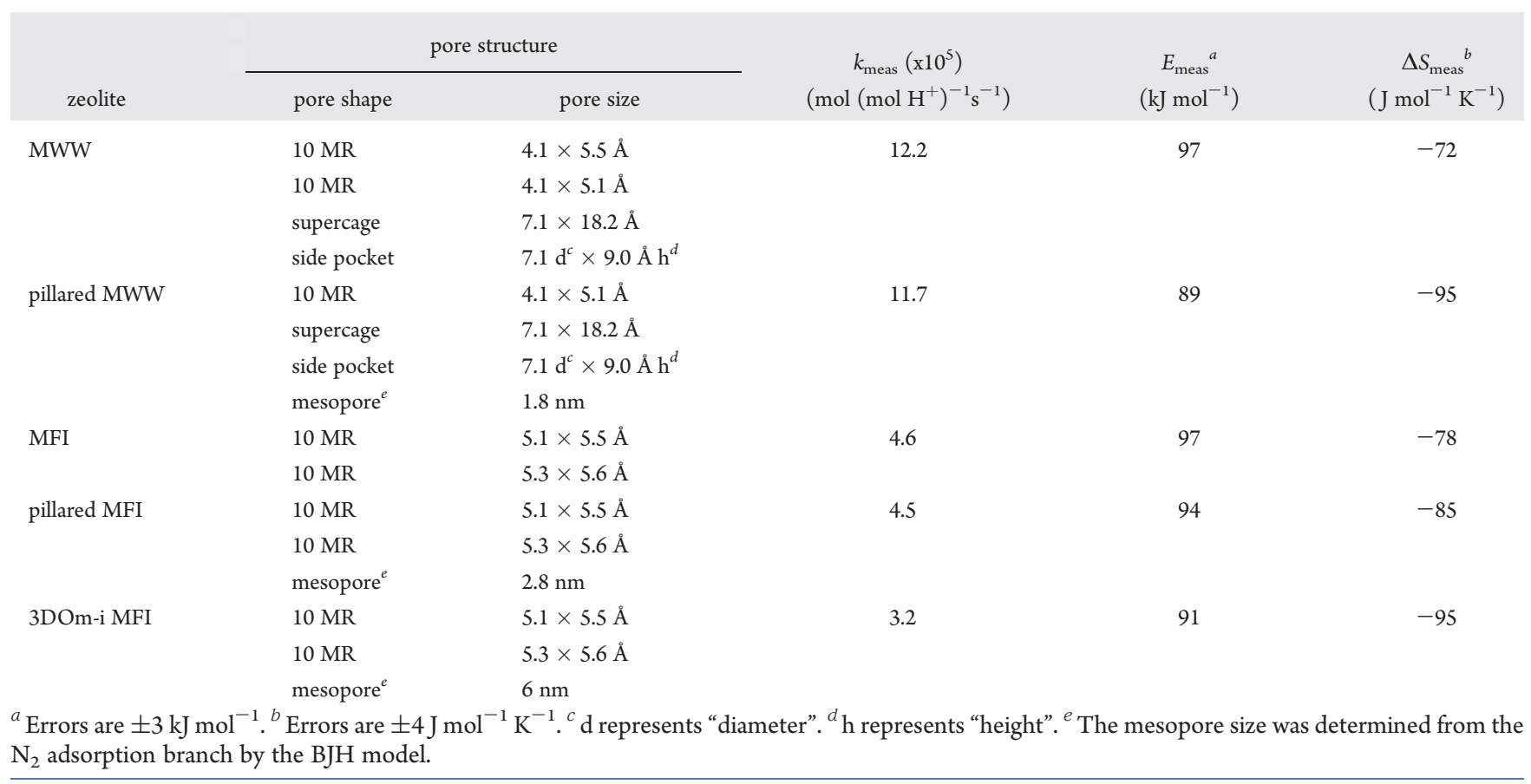

each zeolite catalyst was determined via DME titration experiments assuming that the active Brønsted acid sites participate in reactions of $\mathrm{DME}$ with $\mathrm{H}^{+}$to form surface methyl groups, $\mathrm{CH}_{3} \mathrm{OCH}_{3}+2[\mathrm{SiO}(\mathrm{H}) \mathrm{Al}]=2\left[\mathrm{SiO}\left(\mathrm{CH}_{3}\right) \mathrm{Al}\right]+\mathrm{H}_{2} \mathrm{O}$. All MFI zeolites used in this study adsorbed $0.5 \pm 0.05 \mathrm{DME} / \mathrm{Al}$ upon exposure to DME at $438 \mathrm{~K}$ (Table 1), as expected from stoichiometric methylation of active hydroxyl groups ${ }^{46,47}$ implying that the concentration of Brønsted acid sites is nearly identical to the concentration of $\mathrm{Al}$ in the three zeolite samples. The MWW and pillared MWW adsorbed $0.25 \pm 0.05 \mathrm{DME} / \mathrm{Al}$, which suggests that there is a considerable amount of nonframework $\mathrm{Al}$ in the synthesized MWW and pillared MWW zeolite samples.

3.3. Ethanol Dehydration. Ethanol dehydration has been proposed as a model catalytic reaction to assess the dimensions of the microporous environment of the active acidic hydroxyl group. ${ }^{36,50,51}$ The ethanol dehydration reaction involves the adsorption of ethanol on the Brønsted acid site and the consequent transformation of ethanol into ethylene via a unimolecular reaction or to DEE via a bimolecular reaction. ${ }^{52}$ Ethanol dehydration is predominantly a bimolecular reaction at low temperature while the unimolecular reaction path prevails at high temperature since the formation of ethanol dimeric species is energetically more favorable than the formation of ethanol monomers. ${ }^{37}$ The increase in dimensions of the zeolite channels and cavities should, for given conditions, favor the bimolecular reaction because it allows the accommodation of ethanol dimers. ${ }^{36}$

In the present study, no ethylene was observed in the effluent stream over all MWW or MFI zeolites, indicating that the ethanol dehydration reaction over all these catalysts occurs through a bimolecular pathway consistent with reports in the literature. ${ }^{36,37}$ The pore topology and dimensions of the MWW and MFI zeolites are listed in Table 2. The formation of DEE on MFI is consistent with reports by De las Pozas et al. ${ }^{36}$ and by Chiang et al. ${ }^{37}$ because MFI has $10 \mathrm{MR}$ pore systems and preferentially

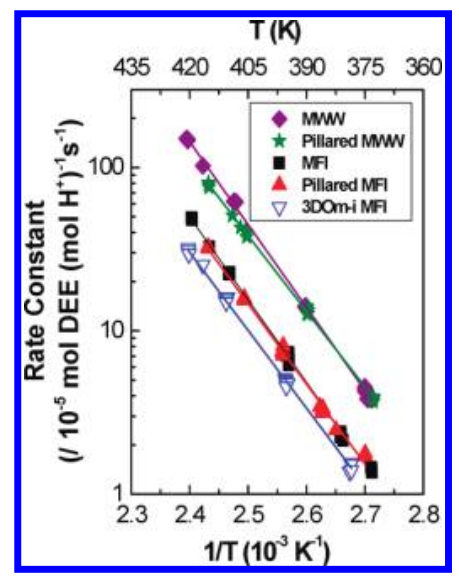

Figure 2. Measured rate constants of DEE production over MWW and MFI zeolite catalysts.

catalyzes bimolecular ethanol dehydration reactions. The production of ethylene was observed only on $\mathrm{HEU}^{36}$ and $\mathrm{MOR}^{36,37,53}$ materials that possess Brønsted acid sties in 8-MR channels. The microporous MWW has $10 \mathrm{MR}$ pores, supercages, and side pockets whose sizes are larger than those of $10 \mathrm{MR}$ channels in MFI. The pillared MWW, pillared MFI, and 3DOm-i MFI zeolites contain even larger mesopores. Therefore, it is easy to rationalize that only DEE is produced in meso-/microporous zeolites.

The Arrhenius plots (the natural logarithm of regressed rate constants versus the inverse temperature) of ethanol dehydration rates over MWW and MFI zeolite catalysts are shown in Figure 2. The plots are parallel to each other which indicates that all zeolite samples have similar activation energies for ethanol dehydration. Table 2 lists the activation energy $\left(\Delta E_{\text {meas }}\right)$, entropies $\left(\Delta S_{\text {meas }}\right)$, and rate constants at $383 \mathrm{~K}\left(k_{\text {meas }}\right)$ for DEE formation over 


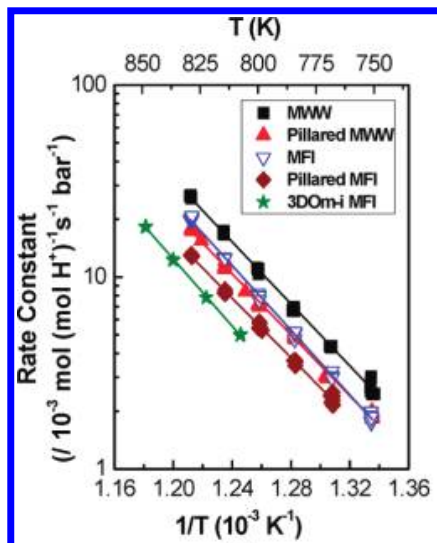

(a)

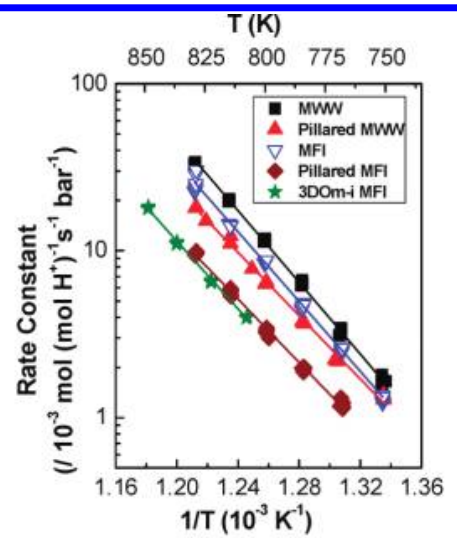

(b)

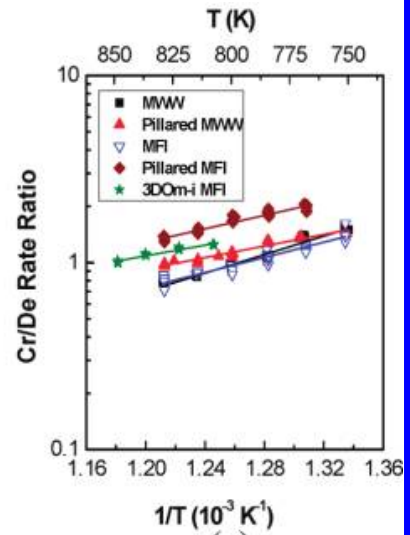

(c)

Figure 3. Arrhenius plots of monomolecular conversion of propane over MWW and MFI zeolite catalysts: (a) cracking (b) dehydrogenation, and (c) temperature dependence of monomolecular propane cracking-to-dehydrogenation ( $\mathrm{Cr} / \mathrm{De})$ rate ratios on MWW and MFI zeolites.

Table 3. Monomolecular Propane Cracking and Dehydrogenation Rate Constants $\left(k_{\text {meas }}\right)$ and Cracking-to-Dehydrogenation $(\mathrm{Cr} / \mathrm{De})$ Rate Ratio at $773 \mathrm{~K}$ and Measured Activation Energies $\left(E_{\text {meas }}\right)$ and Entropies $\left(\Delta S_{\text {meas }}\right)$ on MWW and MFI Zeolites

\begin{tabular}{|c|c|c|c|c|c|c|c|}
\hline \multirow[b]{2}{*}{ zeolite } & \multicolumn{2}{|c|}{$k_{\text {meas }}\left(\times 10^{3}\right)\left(\mathrm{mol}\left(\mathrm{mol} \mathrm{H}^{+}\right)^{-1} \mathrm{~s}^{-1} \mathrm{bar}^{-1}\right)$} & \multirow[b]{2}{*}{$\mathrm{Cr} / \mathrm{De}$ ratio } & \multicolumn{2}{|c|}{$E_{\text {meas }}\left(\mathrm{kJ} \mathrm{mol}^{-1}\right)$} & \multicolumn{2}{|c|}{$\Delta S_{\text {meas }}\left(\mathrm{J} \mathrm{mol}^{-1} \mathrm{~K}^{-1}\right)$} \\
\hline & cracking & dehyd & & cracking $^{a}$ & dehyd $^{b}$ & cracking $^{c}$ & dehyd $^{d}$ \\
\hline MWW & 5.8 & 4.8 & 1.2 & 160 & 202 & -89 & -36 \\
\hline pillared MWW & 3.9 & 3.1 & 1.3 & 159 & 180 & -93 & -67 \\
\hline MFI & 3.8 & 3.5 & 1.1 & 164 & 200 & -86 & -40 \\
\hline pillared MFI & 3.0 & 1.7 & 1.7 & 155 & 183 & -100 & -69 \\
\hline 3DOm-i MFI & 1.9 & 1.2 & 1.6 & 160 & 186 & -97 & -66 \\
\hline${ }^{7}$ Errors are \pm 7 & ${ }^{b}$ Errors & rrors are & ${ }^{1} \mathrm{~K}^{-1} \cdot{ }^{d} \mathrm{H}$ & $s$ are \pm 11 & $\mathrm{I}^{-1} \mathrm{~K}^{-1}$ & & \\
\hline
\end{tabular}

MWW and MFI zeolites. The site time yield of DEE differs among the zeolites by up to a factor of 4 . Measured activation energies $\left(89-97 \mathrm{~kJ} \mathrm{~mol}^{-1}\right.$ ) and entropies (within a range of -95 to $\left.-72 \mathrm{~J} \mathrm{~mol}^{-1} \mathrm{~K}^{-1}\right)$ are comparable among all zeolites. These results imply that Brønsted acid sites in materials possessing dual meso-/microporosity have similar catalytic rates compared to conventional zeolites possessing only micropores when measured under strict kinetic control.

3.4. Monomolecular Conversion of Propane and Isobutane. The accepted pathways for monomolecular reactions of alkanes on zeolites are as follows: an adsorbed alkane onto a Brønsted acid site is protonated to form a penta-coordinated carbonium ion. The carbonium ion may undergo cracking to yield an alkane and an alkoxide species, regenerating the acid site, or it may dehydrogenate to yield $\mathrm{H}_{2}$ and an alkoxide species; the alkoxide species subsequently desorbs to form an alkene and regenerate the Brønsted acid site. ${ }^{42,54-56}$ The measured activation energies $\left(\Delta E_{\text {meas }}\right)$ and entropies $\left(\Delta S_{\text {meas }}\right)$ for the reaction are given by the Temkin's equations: ${ }^{57,58}$

$$
\begin{aligned}
\Delta E_{\text {int }} & =\Delta E_{\text {meas }}-\Delta H_{\text {ads }} \\
\Delta S_{\text {int }} & =\Delta S_{\text {meas }}-\Delta S_{\text {ads }}
\end{aligned}
$$

where $\Delta E_{\text {int }}$ and $\Delta S_{\text {int }}$ are the intrinsic activation energy and intrinsic activation entropy, $\Delta H_{\text {ads }}$ and $\Delta S_{\text {ads }}$ are the adsorption enthalpy and adsorption entropy, respectively. These rate parameters probe the specific structural properties and concomitant effects of spatial confinement in zeolite catalysis. Since the small alkane molecules can diffuse in all pores of the microporous and meso-/microporous zeolite materials, no diffusion limitations affect the reaction rates of the Brønsted acid sites present in these materials, as evaluated by the Mears criteria and reported in sections S.3 and S.4 of Supporting Information. Therefore, the rate and selectivity of alkane conversion for all catalysts tested is related to the intrinsic catalytic behavior of these materials in the absence of pore diffusion limitations.

The Arrhenius plots of the monomolecular conversion of propane (cracking and dehydrogenation) over the zeolite catalysts are shown in Figure 3, panels a and b, respectively. For both the meso-/microporous and microporous MWW and MFI zeolites, the Arrhenius plots of cracking and dehydrogenation reactions were parallel, which indicates that all zeolites have similar activation energies for cracking or dehydrogenation reactions. Figure $3 c$ compares the temperature dependence of propane cracking-to-dehydrogenation rate ratios for the MFI and MWW zeolites studied. The selectivity to cracking or dehydrogenation showed no obvious dependence on the zeolite porosity or types. Table 3 shows rate constants for propane cracking and dehydrogenation and cracking-to-dehydrogenation rate ratios at $773 \mathrm{~K}$ on the zeolite catalysts, together with activation energies and entropies calculated from the temperature dependence of these rate constants. Monomolecular rate constants of cracking or dehydrogenation reactions differ among these zeolites (by up to factors of 4) and even among MWW- or MFI- type samples with different porosities (by up to factors of 3 ). This observation is consistent with a larger variation (a factor of 5 ) in data reported for MFI samples of different provenance ${ }^{43}$ and data reported for different zeolites. ${ }^{38}$ Measured activation energies for dehydrogenation were consistently higher than for cracking (by $21-42 \mathrm{~kJ}$ $\mathrm{mol}^{-1}$ ) on all zeolite catalysts, consistent with activation energies 


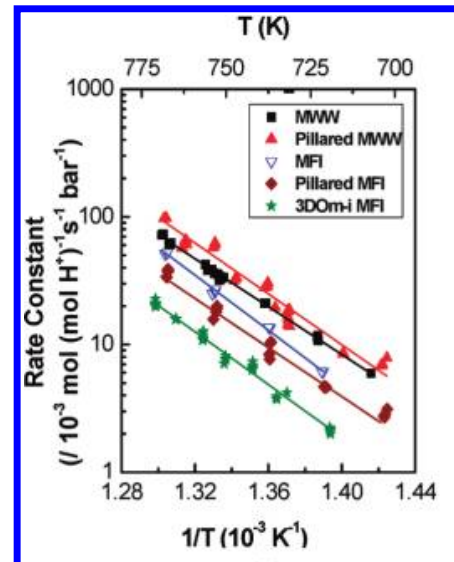

(a)

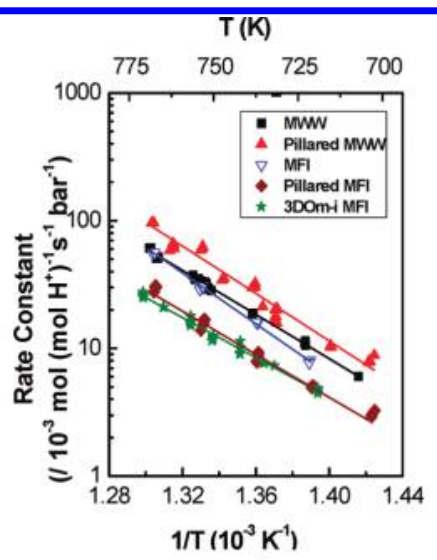

(b)

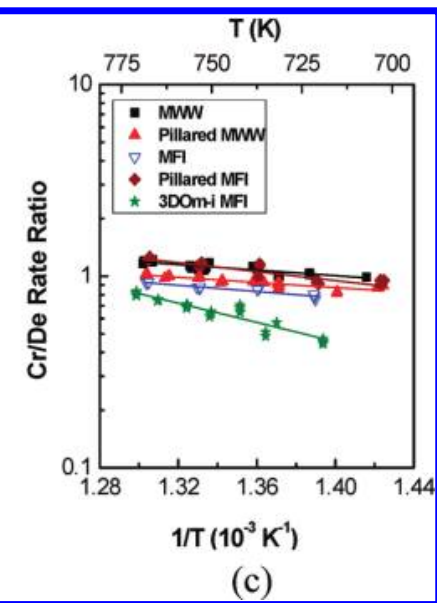

(c)

Figure 4. Arrhenius plots of monomolecular conversion of isobutane over MWW and MFI zeolite catalysts: (a) cracking, (b) dehydrogenation, and (c) temperature dependence of monomolecular isobutane cracking-to-dehydrogenation ( $\mathrm{Cr} / \mathrm{De})$ rate ratios on MWW and MFI zeolites.

Table 4. Monomolecular Isobutane Cracking and Dehydrogenation Rate Constants $\left(k_{\text {meas }}\right)$ and Cracking-to-Dehydrogenation $(\mathrm{Cr} / \mathrm{De})$ Rate Ratio at $748 \mathrm{~K}$ and Measured Activation Energies $\left(E_{\text {meas }}\right)$ and Entropies $\left(\Delta S_{\text {meas }}\right)$ on Zeolites

\begin{tabular}{|c|c|c|c|c|c|c|c|}
\hline \multirow[b]{2}{*}{ zeolite } & \multicolumn{2}{|c|}{$k_{\text {meas }}\left(\mathrm{x} 10^{2}\right)\left(\mathrm{mol}\left(\mathrm{mol} \mathrm{H}^{+}\right)^{-1} \mathrm{~s}^{-1} \mathrm{bar}^{-1}\right)$} & \multirow[b]{2}{*}{$\mathrm{Cr} / \mathrm{De}$ ratio } & \multicolumn{2}{|c|}{$E_{\text {meas }}\left(\mathrm{kJ} \mathrm{mol}^{-1}\right)$} & \multicolumn{2}{|c|}{$\Delta S_{\text {meas }}\left(\mathrm{J} \mathrm{mol}^{-1} \mathrm{~K}^{-1}\right)$} \\
\hline & cracking & dehyd & & cracking $^{a}$ & dehyd $^{b}$ & cracking $^{c}$ & dehyd $^{d}$ \\
\hline MWW & 3.3 & 2.9 & 1.1 & 186 & 161 & -41 & -61 \\
\hline pillared MWW & 4.2 & 4.2 & 1.0 & 191 & 162 & -24 & -41 \\
\hline MFI & 2.2 & 2.3 & 0.9 & 194 & 178 & -8 & -28 \\
\hline pillared MFI & 1.7 & 1.5 & 1.1 & 182 & 160 & -43 & -74 \\
\hline 3DOm-i MFI & 0.9 & 1.3 & 0.7 & 189 & 150 & -28 & -88 \\
\hline
\end{tabular}

for $\mathrm{C}_{3} \mathrm{H}_{8}$ conversion on zeolites MFI, FER, and MOR reported by Gounder et al. ${ }^{43}$ Measured activation entropies are also higher for dehydrogenation than for cracking, consistent with later transition states for dehydrogenation, in which the $\mathrm{H}-\mathrm{H}$ bond is nearly formed at the transition state, ${ }^{59}$ as discussed by Gounder et al. for $\mathrm{C}_{3} \mathrm{H}_{8}$ conversion on zeolites MFI, FER, and MOR zeolites. ${ }^{43}$

Figure 4 panels a and $\mathrm{b}$ show Arrhenius plots for cracking and dehydrogenation reaction pathways of isobutane activation over MWW and MFI zeolites. Similar to propane activation, for both MWW and MFI zeolites, Arrhenius plots for isobutane cracking and dehydrogenation reactions are parallel, implying that all zeolites studied have similar activation energies for cracking and dehydrogenation reactions. The temperature dependence of isobutane cracking-to-dehydrogenation rate ratios on MWW and MFI zeolites is compared in Figure 4c. The selectivity to cracking or dehydrogenation showed no obvious dependence on zeolite porosity or types. The increase in isobutane crackingto-dehydrogenation rate ratios with increasing temperature contrasts with ratios that decreased with temperature for propane as noted above. Table 4 shows rate constants for isobutane cracking and dehydrogenation and cracking-to-dehydrogenation rate ratios at $748 \mathrm{~K}$ on MWW and MFI zeolites, together with activation energies and entropies for both reaction pathways calculated from the temperature dependence of these rate constants. Monomolecular rate constants differ among these zeolites (by up to factors of $\sim 4$ ) and among the same type of MWW or MFI samples with different porosities (by up to factors of $\sim 2$ ). Measured activation energies for dehydrogenation were consistently lower than for cracking (by $16-39 \mathrm{~kJ} \mathrm{~mol}^{-1}$ ) on all samples, a trend opposite to that obtained from the propane reaction results. The larger activation barriers for cracking than for dehydrogenation of isobutane on all of studied zeolite catalysts is consistent with previous reports of isobutane reactions on MOR, MFI, and USY zeolites ${ }^{6-64}$ and with theoretical estimates on 20 T-atom MFI clusters. ${ }^{65}$ The higher activation energy for cracking than for dehydrogenation of isobutane is attributed to the abstraction of hydrogen from isobutane resulting in a tertiary carbenium ion while a less stable secondary carbenium ion is formed upon $\mathrm{C}-\mathrm{C}$ bond scission in isobutane. ${ }^{60}$ Alternatively, the proton affinity of a $\mathrm{C}-\mathrm{H}$ bond is higher than that of a $\mathrm{C}-\mathrm{C}$ bond and hence, it is energetically less demanding to form a three-center-two-electron bond such as $[\mathrm{C}-\mathrm{H}-\mathrm{H}]^{+}$versus a $[\mathrm{C}-\mathrm{H}-\mathrm{C}]^{+}$for isobutane. ${ }^{66}$ Entropy and charge are driving forces for this reaction so that it is expected that the higher charge on the transition state correspondingly requires higher entropy and a looser transition state because the higher charge on the transition state implies greater separation of the positively charged activated complex from the negatively charged lattice oxygen atoms. ${ }^{67}$ The entropy values in meso-/ microporous zeolites for isobutane reactions are consistently higher for cracking than for dehydrogenation in consistence with higher charge and looser transition state for cracking than for dehydrogenation.

Table 5 compares the intrinsic activation energies and entropies for monomolecular propane cracking and dehydrogenation on MWW, pillared MWW, and MFI zeolite catalysts, which were calculated from the measured rate constants (Table 3 ), using Temkin's equations and previously reported adsorption enthalpies and entropies for propane adsorption. ${ }^{25,34}$ It should be mentioned that the propane adsorption enthalpy/entropy of 
Table 5. Adsorption and Intrinsic Kinetic Parameters of Propane Monomolecular Cracking and Dehydrogenation Reactions over MWW and MFI Zeolite Samples

\begin{tabular}{|c|c|c|c|c|c|c|c|c|}
\hline \multirow[b]{2}{*}{ zeolite } & \multicolumn{2}{|c|}{$\Delta H_{\mathrm{ads}}\left(\mathrm{kJ} \mathrm{mol}{ }^{-1}\right)$} & \multicolumn{2}{|c|}{$\Delta S_{\text {ads }}\left(\mathrm{J} \mathrm{mol}^{-1} \mathrm{~K}^{-1}\right)$} & \multicolumn{2}{|c|}{$\Delta E_{\text {int }}\left(\mathrm{kJ} \mathrm{mol}^{-1}\right)$} & \multicolumn{2}{|c|}{$\Delta S_{\text {int }}\left(\mathrm{J} \mathrm{mol}^{-1} \mathrm{~K}^{-1}\right)$} \\
\hline & cracking & dehyd & cracking & dehyd & cracking & dehyd & cracking & dehyd \\
\hline MWW & $-49^{a}$ & $-49^{a}$ & $-113^{a}$ & $-113^{a}$ & 209 & 251 & 24 & 77 \\
\hline pillared MWW & $-49^{a}$ & $-49^{a}$ & $-116^{a}$ & $-116^{a}$ & 208 & 229 & 23 & 49 \\
\hline MFI & $-45^{b}$ & $-45^{b}$ & $-102^{b}$ & $-102^{b}$ & 209 & 245 & 16 & 62 \\
\hline \multicolumn{9}{|l|}{ pillared MFI } \\
\hline 3DOm-i MFI & & & & & & & & \\
\hline
\end{tabular}

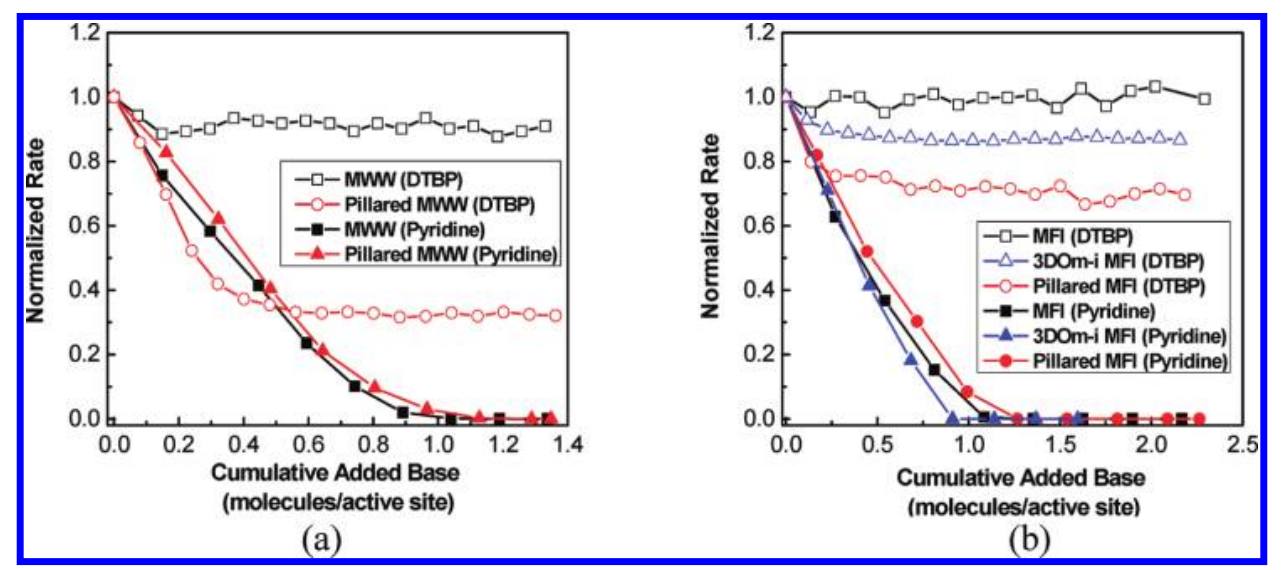

Figure 5. Pyridine or DTBP base titration of acid sites on (a) MWW and (b) MFI zeolite catalysts during ethanol dehydration reactions.

pillared MWW in Table 5 was reported for the pillared MWW material prepared under high temperature swelling conditions. ${ }^{25}$ The energetics of propane adsorption on the pillared MWW synthesized using high temperature swelling conditions were identical to those measured for MWW zeolites at low alkane partial pressure conditions, that is, conditions below a coverage of one alkane molecule per active site. ${ }^{25}$ This result led the authors to conclude that the adsorption of alkanes occurs predominately in the $10 \mathrm{MR}$ channel systems considering that the pillared MWW material contains intact 10 MR channels after swelling and pillaring procedures. ${ }^{49}$ The pillared MWW in the present study synthesized using the procedure reported by Maheshwari et al. ${ }^{14}$ has shown better structural preservation than pillared MWW prepared under high temperature swelling conditions, and thus the adsorption properties between MWW and pillared MWW are expected to be very similar. Consequently, we use the reported propane adsorption enthalpy/entropy of pillared MWW to evaluate the intrinsic kinetic parameters of propane activation over pillared MWW synthesized in the present work. The intrinsic activation barriers (208-209 kJ $\mathrm{mol}^{-1}$ ) for monomolecular $\mathrm{C}_{3} \mathrm{H}_{8}$ cracking, shown in Figure 5, are similar on MWW, pillared MWW, and MFI, in agreement with previous data for $\mathrm{C}_{3} \mathrm{H}_{8}$ cracking on MFI, FER, and MOR zeolites $\left(187-200 \mathrm{~kJ} \mathrm{~mol}^{-1}\right) .{ }^{41,43}$ Their magnitude and insensitivity to zeolite structure also agree with previous reports for $\mathrm{C}_{3} \mathrm{H}_{8}$ cracking on different zeolites MFI, MOR, BEA, and FAU $^{38,68}$ and for the cracking of larger $C_{3}-C_{20}$ n-alkanes on MFI. ${ }^{41,69,70}$ Intrinsic activation energies for monomolecular propane dehydrogenation were also similar on MWW, pillared MWW, and MFI zeolite catalysts $\left(229-251 \mathrm{~kJ} \mathrm{~mol}^{-1}\right)$. No alkane adsorption data for pillared MFI and 3DOm-i MFI are available in the literature so that intrinsic activation energies and entropies of these two materials cannot be calculated and compared with the microporous MFI zeolite. However, the similarity in kinetic behaviors of reactions over pillared MFI, 3DOm-i MFI, and the microporous MFI might imply similar adsorption properties of small alkanes and alcohol molecules on all MFI zeolites studied based on previous reports in the literature that have shown that the intrinsic activation energy for alkane activation is independent of zeolite structure when comparing reactions of alkanes across different zeolites. $38,39,43,68$

The kinetic parameters assessed for propane and isobutane monomolecular reactions consistently show very similar kinetic behavior between zeolites possessing dual meso-/microporosity and microporous zeolites, although these materials have distinct pore structures. The similarity in kinetic behavior of reactions in the present study is in agreement with the results of propane activation over meso-/microporous SAPO and microporous SAPO catalysts reported by Danilina et al. ${ }^{32}$ The apparent rate constant reflects the product of the intrinsic rate constant and the equilibrium constant for adsorption. Adsorption of saturated hydrocarbons in zeolites is primarily due to van der Waals interactions with the walls of the zeolite pore, and these interactions decrease with increasing circumference of the zeolite pore. ${ }^{33,35,71}$ Given that adsorption is a strong function of zeolite pore size or shape, Danilina et al. concluded that the catalytically active sites of the meso-/microporous SAPO are most probably located in the micropores of the sample. ${ }^{32}$ On the basis of the same reasoning, we surmise that mesopores in pillared MWW, pillared MFI, and 3DOm-i MFI have much weaker adsorption interactions for alkanes that would result in a much lower rate for alkane activation. 
Table 6. Comparison of Residual Ethanol Dehydration Rates on MWW and MFI Zeolite Catalysts and DTBP Uptake on Pillared MWW, Pillared MFI, and 3DOm-i MFI Zeolites after Saturation of the Organic Base Titrant Considering a Stoichiometry of One Organic Base Per Brønsted Acid Site

$\begin{array}{lccc}\text { zeolite } & \begin{array}{c}\text { rate loss }{ }^{a} \text { after } \\ \text { pyridine titration } \\ \text { saturation (\%) }\end{array} & \begin{array}{c}\text { rate loss }{ }^{a} \text { after } \\ \text { DTBP titration } \\ \text { saturation (\%) }\end{array} & \begin{array}{c}\text { DTBP }^{b} \text { uptake } \\ \text { after titration } \\ \text { saturation (\%) }\end{array} \\ \text { MWW } & 100 & 8 & \\ \text { Pillared MWW } & 100 & 67 & 60 \\ \text { MFI } & 100 & 0 & 13 \\ \text { 3DOm-i MFI } & 100 & 14 & 29 \\ \text { Pillared MFI } & 100 & 30 & \\ a_{\text {Rate loss was calculated by the following equation: }[1-(\text { residual rate/ }} \\ \text { initial rate) }] \times \text { 100\%. }{ }^{b} \text { DTBP uptake was determined by moles of } \\ \text { adsorbed DTBP over moles of Brønsted acid sites in each catalyst bed } \\ \text { assessed using DME titration experiments. }\end{array}$

Therefore, the comparable rates of propane and isobutane monomolecular reactions and of ethanol reactions for meso-/ microporous and conventional microporous zeolites suggest that the Brønsted acid sites in materials with dual meso-/microporosity are predominantly located in the micropores. However, the presence of significant mesoporosity in the studied meso-/ microporous zeolite materials as inferred from $\mathrm{N}_{2}$ physisorption measurements raises the question: Are active Brønsted acid sites rarely encapsulated in a mesoporous environment? We believe that this is not the case and that a more plausible scenario might be that the active sites in meso-/microporous zeolites are circumscribed in both microporous and mesoporous environments, but under reaction conditions the microporous environment dominates the adsorption properties for small alkane and alcohol reactants because of a better fit of these molecules compared to that in the mesoporous environment as discussed below.

3.5. Base Titration during Ethanol Reaction. To investigate further the surroundings of active sites in the meso-/microporous MWW and MFI zeolites, a series of titration experiments with pyridine or DTBP organic base were conducted during ethanol dehydration reactions. Figure 5a,b shows ethanol dehydration rates as a function of cumulative titrant addition on the MWWand MFI-type zeolites, respectively. Titration with pyridine or DTBP over all zeolites initially resulted in a linear decrease in dehydration rates with increasing addition of the titrant, consistent with stochiometric titration of the active sites along the catalyst bed. At saturation, pyridine suppressed ethanol dehydration rates completely over MWW and MFI zeolites, while DTBP titration maintained different residual rates over the zeolites with different pore structures. The complete loss in dehydration rate upon pyridine titration suggests that less sterically hindered pyridine molecules are transported through the zeolite channels and can access all active Brønsted acid sites in these materials consistent with reports in the literature. ${ }^{72,73}$ The residual ethanol dehydration rates of zeolites after DTBP titration saturation, however, suggests that the bulky DTBP molecules have limited accessibility to Brønsted acid sites located in micropores in MWW- or MFI-type zeolites. ${ }^{74,75}$ The loss in ethanol dehydration rates reflects the degree of accessibility of bulky DTBP molecules to Brønsted acid sites in zeolites with different pore structures, and hence, the number of active sites accessible from the mesoporous environment. The calculation shown in Table 6 indicates that $8 \%$ and $67 \%$ Brønsted acid sites in MWW and pillared MWW, and $0 \%, 14 \%$, and $30 \%$ of Brønsted acid sites in MFI, 3DOm-i MFI, and pillared MFI, respectively, are accessible to DTBP, a molecule that can only be transported via the mesoporous environment in these materials. The possibility of rate loss for ethanol dehydration reactions being caused by pore blockage by the bulky DTBP molecules is excluded as the DTBP uptake on zeolites monitored during titration shows $60 \%, 29 \%$, and $13 \%$ Brønsted acid sites are occupied by the organic base in pillared MWW, pillared MFI, and 3DOm-i MFI, respectively, consistent with the values assessed from the loss in ethanol dehydration rates (Table 6).

The base titration results confirm that some portion of Brønsted acid sites is accessible from the mesoporous environment in meso-/microporous MWW or MFI zeolites and the presence of mesopores increases the accessibility of bulky reactant molecules to the active sites in catalytic reactions. However, when the reaction involves reactant molecules such as ethanol, propane, and isobutane and kinetic studies are conducted in the absence of diffusion limitations as in the present study, the Brønsted acid sites in micro/meso-porous zeolites behave nearly identically to those surrounded only by a microporous environment. Therefore, we conclude that zeolites with dual meso-/ microporosity empower the active acid sites with dual catalytic implications: the microporous environment predominates catalytic behavior of acid sites for reactions conducted without space constraints while the mesoporous environment may provide enhanced accessibility for reactions of larger molecules.

\section{CONCLUSIONS}

Three catalytically active meso-/microporous zeolite materials, pillared MWW, pillared MFI, and 3DOm-i MFI, were synthesized through the creation of mesopores between the microporous zeolite layers by pillaring or by imprinting ordered mesoporosity within single zeolite crystals. Although different pore structures and porosities are present in MWW- and MFItype zeolite materials, the catalytic behavior of Brønsted acid sites in pillared MWW, pillared MFI, and 3DOm-i MFI measured under strict kinetic control is similar to that of their microporous zeolite analogues. The ethanol dehydration reaction shows that meso-/microporous MWW and MFI zeolites have comparable dehydration rates to conventional MWW and MFI zeolites. Monomolecular propane and isobutane reactions measured under differential conversion show that all zeolites studied have consistent cracking and dehydrogenation activation energies, which suggests that Brønsted acid sites behave similarly in conventional zeolites and in the meso-/microporous zeolite. Organic base titration studies during ethanol dehydration show that a fraction of Brønsted acid sites in pillared MWW, pillared MFI, and 3DOm-i MFI can be accessed through the mesopores since the uptake of DTBP titrant by the catalyst is consistent with the decrease in ethanol dehydration rates. On the basis of these results, we conclude that some Brønsted acid sites in zeolites containing dual meso-/microporosities are circumscribed by both microporous and mesoporous environments and that the catalytic behavior of these Brønsted acid sites is primarily dominated by the micropores and remains largely unaffected by the presence of mesopores when assessed in rigorous kinetic measurements in the absence of transport restrictions using probe $\mathrm{C}_{3}-\mathrm{C}_{4}$ alkane and alcohol reactants. 


\section{ASSOCIATED CONTENT}

S Supporting Information. Experimental methods for synthesis of MWW, pillared MWW, pillared MFI, and 3DOm-i MFI zeolites; SEM, XRD, SAXD, BET, solid state NMR, and DME titration characterization procedures; assessment of external and internal diffusion limitations in alkane activation; and discussion on textural properties of zeolite catalysts based on the SEM, XRD, SAXD, BET, solid state NMR analysis results. This material is available free of charge via the Internet at http://pubs.acs.org.

\section{AUTHOR INFORMATION}

\section{Corresponding Author}

*A.B.: Phone: $(+1)$ 612-626-3981. E-mail: abhan@umn.edu. Fax: $(+1)$ 612- 626-7246. M.T.: Phone: $(+1)$ 612-626-0920. E-mail: tsapatsis@umn.edu. Fax: (+1) 612-626-7246.

\section{ACKNOWLEDGMENT}

The authors gratefully acknowledge financial support from the Petroleum Institute of Abu Dhabi through the ADMIRE (Abu Dhabi-Minnesota Institute for Research Excellence) partnership, the National Science Foundation (NSF-EFRI 0937706), and IREE. Portions of this work were carried out at the University of Minnesota, College of Science and Engineering Characterization Facility, which receives partial support from NSF through the NNIN program.

\section{REFERENCES}

(1) Corma, A. Chem. Rev. 1997, 97, 2373-2420.

(2) Corma, A. J. Catal. 2003, 216, 298-312.

(3) Cundy, C. S.; Cox, P. A. Chem. Rev. 2003, 103, 663-701.

(4) Čejka, J.; Mintova, S. Catal. Rev. - Sci. Eng. 2007, 49, 457-509.

(5) Davis, M. E. Nature 2002, 417, 813-821.

(6) Bhan, A.; Iglesia, E. Acc. Chem. Res. 2008, 41, 559-567.

(7) Davis, M. E. Chem.-Eur. J. 1997, 3, 1745-1750.

(8) Tao, Y. S.; Kanoh, H.; Abrams, L.; Kaneko, K. Chem. Rev. 2006, 106, 896-910.

(9) Perez-Ramirez, J.; Christensen, C. H.; Egeblad, K.; Christensen, C. H.; Groen, J. C. Chem. Soc. Rev. 2008, 37, 2530-2542.

(10) Egeblad, K.; Christensen, C. H.; Kustova, M. Chem. Mater. 2008, 20, 946-960.

(11) Corma, A.; Fornes, V.; Pergher, S. B.; Maesen, T. L. M.; Buglass, J. G. Nature 1998, 396, 353-356.

(12) Kresge, C. T.; Roth, W. J.; Simmons, K. G.; Vartuli, J. C. (Mobil Oil Corporation) WO Patent 92/011935, 1992.

(13) Barth, J. O.; Jentys, A.; Kornatowski, J.; Lercher, J. A. Chem. Mater. 2004, 16, 724-730.

(14) Maheshwari, S.; Jordan, E.; Kumar, S.; Bates, F. S.; Penn, R. L.; Shantz, D. F.; Tsapatsis, M. J. Am. Chem. Soc. 2008, 130, 1507-1516.

(15) Tao, Y. S.; Kanoh, H.; Kaneko, K. J. Am. Chem. Soc. 2003, 125, 6044-6045.

(16) Choi, M.; Cho, H. S.; Srivastava, R.; Venkatesan, C.; Choi, D. H.; Ryoo, R. Nat. Mater. 2006, 5, 718-723.

(17) Jacobsen, C. J. H.; Madson, C.; Houzvicka, J.; Schmidt, I.; Carlsson, A. J. Am. Chem. Soc. 2000, 122, 7116-7117.

(18) Fan, W.; Snyder, M. A.; Kumar, S.; Lee, P.-S.; Yoo, W. C.; V., M. A.; Penn, R. L.; Stein, A.; Tsapatsis, M. Nat. Mater. 2008, 7, 984-991.

(19) Groen, J. C.; Bach, T.; Ziese, U.; Donk, A.; de Jong, K. P.; Moulijn, J. A.; Perez-Ramirez, J. J. Am. Chem. Soc. 2005, 127, 10792-10793.

(20) Wang, Q. L.; Giannetto, G.; Torrealba, M.; Perot, G.; Kappenstein, C.; Guisnet, M. J. Catal. 1991, 130, 459-470.

(21) Choi, M.; Na, K.; Kim, J.; Sakamoto, Y.; Terasaki, O.; Ryoo, R. Nature 2009, 461, 246-246.
(22) Maheshwari, S.; Martínez, C.; Portilla, M. T.; Llopis, F. J.; Corma, A.; Tsapatsis, M. J. Catal. 2010, 272, 298-308.

(23) Mallon, E. E.; Bhan, A.; Tsapatsis, M. J. Phys. Chem. B 2010, 114, 1939-1945.

(24) Rubin, M. K.; Chu, P. U.S. Patent 4954325, 1990.

(25) He, Y. J.; Nivarthy, G. S.; Eder, F.; Seshan, K.; Lercher, J. A. Microporous Mesoporous Mater. 1998, 25, 207-224.

(26) Laforge, S.; Ayrault, P.; Martin, D.; Guisnet, M. Appl. Catal., A 2005, 279, 79-88.

(27) Na, K.; Choi, M.; Park, W.; Sakamoto, Y.; Terasaki, O.; Ryoo, R. J. Am. Chem. Soc. 2010, 132, 4169-4177.

(28) Yokoi, T.; Sakamoto, Y.; Terasaki, O.; Kubota, Y.; Okubo, T.; Tatsumi, T. J. Am. Chem. Soc. 2006, 128, 13664-13665.

(29) Davis, T. M.; Snyder, M. A.; Krohn, J. E.; Tsapatsis, M. Chem. Mater. 2006, 18, 5814-5816.

(30) Snyder, M. A.; Lee, J. A.; Davis, T. M.; Scriven, L. E.; Tsapatsis, M. Langmuir 2007, 23, 9924-9928.

(31) Lee, P.-S.; Fan, W.; Zhang, X.; Al Hashimi, S.; Tsapatsis, M. Microporous Mesoporous Mater., submitted for publication.

(32) Danilina, N.; Krumeich, F.; van Bokhoven, J. A. J. Catal. 2010, 272, 37-43.

(33) Eder, F.; Lercher, J. A. Zeolites 1997, 18, 75-81.

(34) Eder, F.; Stockenhuber, M.; Lercher, J. A. J. Phys. Chem. B 1997, $101,5414-5419$.

(35) Savitz, S.; Siperstein, F.; Gorte, R. J.; Myers, A. L. J. Phys. Chem. B 1998, 102, 6865-6872.

(36) Pozas, C. d. 1.; Lopez-Cordero, R.; Gonzalez-Morales, J. A.; Travieso, N.; Roque-Malherbe, R. J. Mol. Catal. 1993, 83, 145-156.

(37) Chiang, H.; Bhan, A. J. Catal. 2010, 271, 251-261.

(38) Xu, B.; Sievers, C.; Hong, S. B.; Prins, R.; van Bokhoven, J. A. J. Catal. 2006, 244, 163-168.

(39) Swisher, J. A.; Hansen, N.; Maesen, T.; Keil, F. J.; Smit, B.; Bell, A. T. J. Phys. Chem. C 2010, 114, 10229-10239.

(40) Haag, W. O.; Lago, R. M.; Weisz, P. B. Faraday Discuss. 1981, $72,317-330$.

(41) Narbeshuber, T. F.; Vinek, H.; Lercher, J. A. J. Catal. 1995, 157, 388-395.

(42) Kotrel, S.; Knozinger, H.; Gates, B. C. Microporous Mesoporous Mater. 2000, 35-6, 11-20.

(43) Gounder, R.; Iglesia, E. J. Am. Chem. Soc. 2009, 131, 1958-1971.

(44) Corma, A.; Fornés, V.; Martínez-Triguero, J.; Pergher, S. B. J. Catal. 1999, 186, 57-63.

(45) Barth, J. O.; Kornatowski, J.; Lercher, J. A. J. Mater. Chem. 2002, $12,369-373$.

(46) Cheung, P.; Bhan, A.; Sunley, G. J.; Iglesia, E. Angew. Chem., Int. Ed. 2006, 45, 1617-1620.

(47) Cheung, P.; Bhan, A.; Sunley, G. J.; Law, D. J.; Iglesia, E. J. Catal. 2007, 245, 110-123.

(48) Leonowicz, M. E.; Lawton, J. A.; Lawton, S. L.; Rubin, M. K. Science 1994, 264, 1910-1913.

(49) Roth, W. J.; Kresge, C. T.; Vartuli, J. C.; Leonowicz, M. E.; Fung, A. S.; McCullen, S. B. In Catalysis by Microporous Materials, Studies in Surface Science and Catalysis; Beyer, H.K., Kiricsi, I., Nagy, J. B., Eds.; Elsevier: Amsterdam, The Netherlands, 1995; Vol. 94, pp 301-308.

(50) Kondo, J. N.; Ito, K.; Yoda, E.; Wakabayashi, F.; Domen, K. J. Phys. Chem. B 2005, 109, 10969-10972.

(51) Deng, J. F.; Zhang, G. R.; Dong, S. H.; Pan, H. S.; Wang, H. M. Appl. Catal., A 1988, 41, 13-22.

(52) Phillips, C. B.; Datta, R. Ind. Eng. Chem. Res. 1997, 36, 4466-4475.

(53) Zhu, Q. J.; Kondo, J. N.; Inagaki, S.; Tatsumi, T. Top. Catal. 2009, 52, 1272-1280.

(54) Haag, W. O.; Dessau, R. M. In Proceedings of the 8th International Congress on Catalysis, Vol. 2, Berlin, Germany, July 2-6, 1984, Verlag Chemie, Weinheim, p 305.

(55) Olah, G. A.; Halpern, Y.; Shen, J.; Mo, Y. K. J. Am. Chem. Soc. 1973, 95, 4960-4970.

(56) Lercher, J. A.; Vansanten, R. A.; Vinek, H. Catal. Lett. 1994, 27, 91-96. 
(57) Temkin, M. I. Adv. Catal. 1979, 28, 173-281.

(58) Bhan, A.; Gounder, R.; Macht, J.; Iglesia, E. J. Catal. 2008, 253, 221-224.

(59) Zheng, X. B.; Blowers, P. J. Phys. Chem. A 2005, 109, 1073410741.

(60) Stefanadis, C.; Gates, B. C.; Haag, W. O. J. Mol. Catal. 1991, 67, 363-367.

(61) Lombardo, E. A.; Hall, W. K. J. Catal. 1988, 112, 565-578.

(62) Narbeshuber, T. F.; Brait, A.; Seshan, K.; Lercher, J. A. J. Catal. 1997, 172, 127-136.

(63) Corma, A.; Miguel, P. J.; Orchilles, A. V. J. Catal. 1994, 145, 171-180.

(64) Yaluris, G.; Rekoske, J. E.; Aparicio, L. M.; Madon, R. J.; Dumesic, J. A. J. Catal. 1995, 153, 54-64.

(65) Milas, I.; Nascimento, M. A. C. Chem. Phys. Lett. 2003, 373, 379-384.

(66) Bucko, T.; Benco, L.; Hafner, J.; Angyan, J. G. J. Catal. 2007, 250, 171-183.

(67) Gounder, R.; Iglesia, E. Angew. Chem., Int. Ed. 2010, 49, 808-811.

(68) Van Bokhoven, J. A.; Williams, B. A.; Ji, W.; Koningsberger, D. C.; Kung, H. H.; Miller, J. T. J. Catal. 2004, 224, 50-59.

(69) Olson, D. H.; Haag, W. O.; Lago, R. M. J. Catal. 1980, 61, 390-396.

(70) Wei, J. Chem. Eng. Sci. 1996, 51, 2995-2999.

(71) Eder, F.; Lercher, J. A. J. Phys. Chem. B 1997, 101, 1273-1278.

(72) Thibault-Starzyk, F.; Stan, I.; Abello, S.; Bonilla, A.; Thomas, K.; Fernandez, C.; Gilson, J. P.; Perez-Ramirez, J. J. Catal. 2009, 264, $11-14$.

(73) Bevilacqua, M.; Montanari, T.; Finocchio, E.; Busca, G. Catal. Today 2006, 116, 132-142.

(74) Macht, J.; Baertsch, C. D.; May-Lozano, M.; Soled, S. L.; Wang, Y.; Iglesia, E. J. Catal. 2004, 227, 479-491.

(75) Farcasiu, D.; Leu, R.; Corma, A. J. Phys. Chem. B 2002, 106, 928-932.

\section{NOTE ADDED AFTER ASAP PUBLICATION}

Due to a production error, the version of this paper that was published on the Web December 10, 2010, contained the wrong Supporting Information document. The correct document was published December 16, 2010. 